\title{
KẾT QUẢ ĐIỀU TRI BỆNH ĐộNG MẠCH CHI DƯớI BẰNG PHẪU THUẬT PHỐI HỘP VỚI CAN THIỆP MẠCH MÁU MỘT THÌ (HYBRID) TẠI BỆNH VIỆN HŨU NGHỊ VIỆT ĐỨC GIAI ĐOẠN 2014 - 2015
}

Nguyễn Duy Thắng*, Đoàn Quốc Hung**

\section{TÓM TĂT}

Phối hợp phẫu thuật và can thiệp nội mạch một thì (hybrid) cho bệnh mạch máu chi dưới đã được tiến hành tại bệnh viện Việt Đức từ 2011 với kết quả ban đầu tương đối tốt. Chúng tôi tiếp tục tiến hành biện pháp điều trị này cho $\mathrm{BN}$ có chỉ định giai đoạn 2014-2015. Kết quả: có 14 BN được tiến hành điều trị trong đó có $8 \mathrm{BN}$ thiếu máu giai đoạn III, 6 BN thiếu máu giai đoạn IV theo phân loại Leriche-Fontaine. Chỉ có $1 \mathrm{BN}$ nữ, tuổi trung bình của $\mathrm{BN}$ là 72,7 . Có $28,6 \% \mathrm{BN}$ có tổn thương $\mathrm{TBMN}$ cũ, $21,4 \% \mathrm{BN}$ có tổn thương mạch cảnh hoặc mạch vành cần can thiệp kèm theo. Tất cả các BN đều giảm/ hết đau sau điều trị. $\mathrm{ABI}$ trung bình của chi đau tăng từ 0,32 lên 0,73 . Chỉ có một $\mathrm{BN}$ phải cắt cụt $1 / 3$ dưới cẳng chân do có hoại tử bàn chân từ trước. Tắc cầu nối sau mổ gặp 1 trường hợp. Cắt cụt tối thiếu sau điều trị chỉ chiếm $21,43 \%$. Không có biến chứng về kỹ thuật trong quá trình điều trị. Hybrid cho những tổn thương nhiều tầng của bệnh $\mathrm{ĐM}$ chi dưới vẫn là một biện pháp an toàn, hiệu quả và nên được áp dụng. Tì khóa: Bệnh ĐM chi dưới, Phẫu thuật mạch máu, can thiệp mạch máu, hybrid

SUMMARY: Combining open surgery and endovascular interventions (Hybrid) for peripheral artery disease (PAD) were first conducted in Viet-Duc hospital since 2011 with good initial results. We continue this therapy for patients with PAD in 2014 - 2015 Results: 14 patients were treated including 8 stage III patients, 6 stage IV patients (Leriche-Fontaine's classification). Only one female patient, Average age of patients was 72.7. There are $28.6 \%$ patients had previous CVA lesions, 21.4\% patients with carotid or coronary lesions. All patients were reduced /free from pain after treatment. Ankle Brachial Index (ABI) rose from 0.32 to 0.73 . Only one patient required major amputation. Minor amputation after treatment accounted for $21.43 \%$. No technical complications happen during treatment. Hybrid for multi-stage lesions of PAD remains safety, effective and feasible. Keywords: PAD, vascular surgery, vascular intervention, hybrid.

\section{I. ĐẶT VẤN ĐỀ}

Cùng với tuổi thọ trung bình tăng cao, tỷ lệ bệnh chuyển hóa ngày càng nhiều và sự thay đổi chế độ dinh dưỡng, số lượng bệnh nhân $(\mathrm{BN})$ có bệnh mạch máu nói chung và bệnh động mạch (ĐM) chi dưới nói riêng tại Việt Nam diễn biến theo xu hướng tăng dần về số lượng $\mathrm{BN}$ cũng như mức độ phức tạp của bệnh. Can thiệp nội mạch phối hợp với phẫu thuật mạch máu (Hybrid) cho các $\mathrm{BN}$ có bệnh $Đ M$ chi dưới bắt đầu được triển khai tại bệnh viện Việt Đức từ tháng 10/2011 với sự giúp đỡ của các chuyên gia Pháp[0],[0]. Kết quả điều trị cho các BN giai đoạn 2011- 2013 là tương đối khả quan tuy nhiên cỡ mẫu còn hạn chế do chi phí điều trị còn cao và kinh nghiệm điều trị của chúng tôi còn hạn chế [0]. Tiếp tục thành công của những $\mathrm{BN}$ ban đầu này, chúng tôi tiếp tục áp dụng phương pháp điều trị này cho các $\mathrm{BN}$ có bệnh ĐM chi dưới giai đoạn 2014-2015. Nghiên cứu này đánh giá kết quả của áp dụng hybrid trong điều trị bệnh $Đ \mathrm{OM}$ chi dưới nhằm rút ra kết luận về chỉ định, đặc điểm bệnh nhân, ưu nhược điểm, kết quả, khả năng ứng dụng và phát triển.

\footnotetext{
* Khoa phẫu thuật tim mạch Bệnh viện HN Việt Đức ** Bộ môn Ngoại, ĐHY Hà Nội Người chịu trách nhiệm khoa học: PGS.TS. Đoàn Quốc Hung Ngày nhận bài: 15/10/2016 - Ngày Cho Phép Đăng: 05/11/2016 Phản Biện Khoa học: PGS.TS. Đặng Ngoc Hùng
} GS.TS. Bùi Đúc Phú 


\section{II. ĐỐI TƯợNG VÀ PHƯơng PHÁP NGHIÊN CÚU}

Nghiên cứu can thiệp tiến cứu, $\mathrm{BN}$ được chẩn đoán bệnh $Đ M$ chi dưới tại bệnh viện hữu nghị Việt Đức giai đoạn 12/2014 - 09/2015. Có chỉ định phục hồi lưu thông mạch máu (thiếu máu chi giai đoạn III, IV theo phân loại LericheFontaine). Tổn thương mạch máu được chia thành 3 tầng: Tổn thương mạch chủ chậu, tổn thương mạch đùi khoeo trên gối và tổn thương mạch dưới gối. BN có ít nhất hai tầng tổn thương trong đó phương pháp ưu tiên phục hồi lưu thông mạch máu trên mỗi tầng khác nhau theo guidelines châu Âu và Mỹ[0],[0].[0]. Can thiệp nội mạch được thực hiện trước, sau hoặc đồng thời với can thiệp phẫu thuật trong một lần gây mê/gây tê. Các thăm dò trước mổ gồm lâm sàng, sinh hóa, chức năng gan thận,đông máu, điện tim, siêu âm tim, siêu âm doppler mạch, chụp cắt lớp vi tính, chụp ĐM, chỉ số huyết áp mắt cá chân cánh tay (ABI: Ankle Brachial Index). Tiền sử bệnh phối hợp và yếu tố nguy cơ (hút thuốc lá, thuốc lào, đái tháo đường, tăng huyết áp, mỡ máu), tiền sử phẫu thuật được ghi nhận chi tiết. Hybrid được tiến hành tại phòng can thiệp và phẫu thuật tim mạch, khoa phẫu thuật tim mạch và lồng ngực bệnh viện hữu nghị Việt Đức. Máy C-arm trong can thiệp là hệ thống GE 9900 Lite của General Electric. Thuốc cản quang sử dụng là Telebrix và Ultravist. Bóng nong, Stent trong can thiệp được sử dụng của các hãng Medtronic và Cook (Hoa Kỳ). Mạch nhân tạo trong phẫu thuật là mạch của hãng B.Braun. Sau điều trị bệnh nhân được đánh giá bằng siêu âm và hoặc Scanner tại bệnh viện Hữu nghị Việt Đức. Diễn biến trong quá trình phẫu thuật/thủ thuật, kết quả, biến chứng được thống kê, phân tích, so sánh từ đó đưa ra các nhận xét về chỉ định và kết quả của hybrid, đề xuất ý kiến thích hợp.

\section{KẾT QUẢ}

Trong thời gian tù tháng 12/2014 tới tháng 9/2015, có 14 bệnh nhân có bệnh ĐM chi duoói hội đủ các chỉ tiêu nghiên cứu được phân bố nhu sau: nam 13 (tỷ lệ 92,86\%); tuổi thấp nhất 51 cao nhất 86, trung bình 72,7 tuổi.

Bảng 1: Đặc điểm lâm sàng của bệnh nhân

\begin{tabular}{|l|l|c|c|}
\hline \multicolumn{2}{|c|}{ Đặc điểm } & $\begin{array}{c}\text { Số } \\
\text { lượng }\end{array}$ & $\begin{array}{c}\text { Tỷ lệ } \\
\%\end{array}$ \\
\hline \multirow{2}{*}{ Tiền sử } & Hút thuốc & 12 & 85,71 \\
\cline { 2 - 4 } & Mổ cũ* & 3 & 21,43 \\
\hline Chẩn đoán & $\begin{array}{l}\text { Thiếu máu giai } \\
\text { đoạn III }\end{array}$ & 8 & 57,14 \\
\cline { 2 - 4 } & $\begin{array}{l}\text { Thiếu máu giai } \\
\text { đoạn IV }\end{array}$ & 6 & 42,86 \\
\hline \multirow{2}{*}{$\begin{array}{l}\text { Tổn } \\
\text { thương } \\
\text { phối hợp }\end{array}$} & $\begin{array}{l}\text { TBMN cũ có di } \\
\text { chứng liệt }\end{array}$ & 4 & 28,57 \\
\cline { 2 - 4 } & $\begin{array}{l}\text { Tổn thương } \\
\text { mạch cảnh }\end{array}$ & 2 & 14,28 \\
\cline { 2 - 4 } & $\begin{array}{l}\text { Tổn thương } \\
\text { mạch vành }\end{array}$ & 1 & 7,14 \\
\cline { 2 - 4 } & $\begin{array}{l}\text { U phổi, tràn dịch } \\
\text { màng phổi }\end{array}$ & 1 & 7,14 \\
\hline \multirow{2}{*}{$\begin{array}{l}\text { Đặc điểm } \\
\text { phẫu thuật }\end{array}$} & Bán cấp cứu & 3 & 21,43 \\
\cline { 2 - 4 } & Mổ phiên & 11 & 78,57 \\
\hline
\end{tabular}

*: 1 trường hợp đã cắt cụt đùi trái do tắc mạch.

2 trường hợp đã bắc cầu đùi khoeo 2 bên.

Phương pháp điều trị Hybrid cho các BN được thể hiện ở bảng sau: 
Bảng 2: Phương pháp điều trị cho các BN

\begin{tabular}{|c|c|c|c|}
\hline Chẩn đoán bệnh & Tầng tổn thương & Cách can thiệp & Cách phẫu thuật \\
\hline $\begin{array}{l}\text { Thiếu máu giai đoạn III } 2 \\
\text { chân }\end{array}$ & $\begin{array}{l}\text { Đùi khoeo - dưới } \\
\text { gối } 2 \text { chân }\end{array}$ & $\begin{array}{l}\text { Chụp mạch chẩn đoán, } \\
\text { kiểm tra }\end{array}$ & Lấy HK ĐM 2 chân \\
\hline $\begin{array}{l}\text { Thiếu máu g/đ III chân P, } \\
\text { II chân T }\end{array}$ & $\begin{array}{c}\text { Chậu } 2 \text { bên }- \text { đùi } \\
\text { khoeo } \mathrm{P}\end{array}$ & Stent ĐM chậu T & $\begin{array}{l}\text { Bóc nội mạc, bắc cầu } \\
\text { đùi đùi } \mathrm{T}-\mathrm{P}\end{array}$ \\
\hline Thiếu máu g/đ IV chân T & $\begin{array}{c}\text { Chậu - đùi khoeo - } \\
\text { dưới gối } 2 \text { bên }\end{array}$ & $\begin{array}{l}\text { Nong ĐM đùi nông } \mathrm{T} \\
\text { bằng bóng }\end{array}$ & Bắc cầu đùi đùi $\mathrm{P}-\mathrm{T}$ \\
\hline Thiếu máu g/đ IV chân P & Chậu - đùi khoeo P & $\begin{array}{l}\text { Nong và đặt stent ĐM } \\
\text { chậu P }\end{array}$ & Bóc nội mạc ĐM đùi $\mathrm{P}$ \\
\hline Thiếu máu g/đ IV chân $P$ & $\begin{array}{c}\text { Chậu - đùi khoeo } 2 \\
\text { bên }\end{array}$ & $\begin{array}{l}\text { Stent ĐM chậu } \mathrm{T} \text {, nong } \\
\text { ĐM đùi nông } \mathrm{P}\end{array}$ & $\begin{array}{l}\text { Bóc nội mạc, bắc cầu } \\
\text { đùi đùi T - P }\end{array}$ \\
\hline Thiếu máu g/đ IV chân P & $\begin{array}{c}\text { Chậu } 2 \text { bên - đùi } \\
\text { khoeo } \mathrm{P}\end{array}$ & Stent ĐM chậu T & bắc cầu đùi đùi $\mathrm{T}-\mathrm{P}$ \\
\hline Thiếu máu G/đ III chân P & Chậu - đùi khoeo P & Đặt stent ĐM chậu P & $\begin{array}{l}\text { Bắc cầu đùi khoeo } \\
\text { bằng mạch nhân tạo }\end{array}$ \\
\hline $\begin{array}{l}\text { Thiếu máu g/đ IV do Tắc } \\
\text { cầu đùi khoeo T/ }\end{array}$ & $\begin{array}{c}\text { Đùi khoeo - dưới } \\
\text { gối chân T }\end{array}$ & $\begin{array}{l}\text { Nong ĐM chân T dưới } \\
\text { gối }\end{array}$ & $\begin{array}{l}\text { Lấy HK mạch nhân } \\
\text { tạo }\end{array}$ \\
\hline Thiếu máu g/đ III chân T & $\begin{array}{c}\text { Chậu } 2 \text { bên - đùi } \\
\text { khoeo }\end{array}$ & Stent ĐM chậu P & Bắc cầu đùi đùi $\mathrm{P}-\mathrm{T}$ \\
\hline Thiếu máu g/đ III chân P & $\begin{array}{c}\text { Chậu } 2 \text { bên - đùi } \\
\text { khoeo } \mathrm{P}\end{array}$ & Stent ĐM chậu T & $\begin{array}{l}\text { Bóc nội mạc, bắc cầu } \\
\text { đùi đùi } \mathrm{T}-\mathrm{P}\end{array}$ \\
\hline Thiếu máu g/đ IV chân T & $\begin{array}{c}\text { Chậu } 2 \text { bên }- \text { dưới } \\
\text { gối } \mathrm{T}\end{array}$ & Stent ĐM chậu P & $\begin{array}{l}\text { bóc nội mạc, bắc cầu } \\
\text { đùi đùi } \mathrm{P}-\mathrm{T}\end{array}$ \\
\hline Thiếu máu g/đ III chân P & $\begin{array}{c}\text { Chậu } 2 \text { bên }- \text { đùi } \\
\text { khoeo } \mathrm{P}\end{array}$ & $\begin{array}{l}\text { Nong ĐM đùi nông } \mathrm{P} \\
\text { bằng bóng }\end{array}$ & $\begin{array}{l}\text { Bóc nội mạc, bắc cầu } \\
\text { đùi đùi T-P }\end{array}$ \\
\hline $\begin{array}{l}\text { Thiếu máu G/đ III do tắc } \\
\text { cầu đùi-khoeo } \mathrm{P}\end{array}$ & $\begin{array}{c}\text { Đùi khoeo - dưới } \\
\text { gối P }\end{array}$ & $\begin{array}{l}\text { Nong miệng nối dưới } \\
\text { bằng bóng }\end{array}$ & $\begin{array}{l}\text { Lấy KH mạch nhân } \\
\text { tạo }\end{array}$ \\
\hline $\begin{array}{l}\text { Thiếu máu g/đ III do tắc } \\
\text { cầu đùi khoeo } \mathrm{P}\end{array}$ & $\begin{array}{c}\text { Chậu P- đùi khoeo } \\
\text { P }\end{array}$ & Stent ĐM chậu P & $\begin{array}{l}\text { Bắc cầu đùi khoeo } \mathrm{P} \\
\text { bằng TM hiển }\end{array}$ \\
\hline
\end{tabular}

Kết quả: Thời gian nằm viện trung bình là 8,6 ngày, ngắn nhất là 5 ngày, dài nhất là 20 ngày. ABI trung bình tăng từ $0,32 \pm 0,10(0,1$ đến 0,4$)$ lên $0,73 \pm 0,13(0,55$ đến 0,95$))(\mathrm{p}<0,05)$. Tỷ lệ cắt cụt và biến chứng được thể hiện ở bảng sau: 
Bảng 3: Kết quả điều trị Hybrid.

\begin{tabular}{|c|c|c|c|c|}
\hline \multicolumn{2}{|c|}{ Kết quả } & Số BN & Tỷ lệ \% & Tổng (\%) \\
\hline \multirow[t]{2}{*}{ Cải thiện đau } & Hết đau & 8 & 57,1 & \multirow[t]{2}{*}{100} \\
\hline & Giảm đau & 6 & 42,9 & \\
\hline \multicolumn{2}{|c|}{ Thành công về kỹ thuật } & 14 & \multicolumn{2}{|c|}{100} \\
\hline \multirow[t]{2}{*}{ Bảo tồn chi } & Cắt cụt lớn & $1^{*}$ & 7,14 & \multirow[t]{2}{*}{28,57} \\
\hline & Cắt cụt ngón & 3 & 21,42 & \\
\hline \multirow[t]{3}{*}{ Biến chứng } & Chảy máu & 0 & 0 & \multirow[t]{3}{*}{0} \\
\hline & Mồ lại & 0 & 0 & \\
\hline & Nhiễm trùng & 0 & 0 & \\
\hline \multirow[t]{2}{*}{ Doppler sau mồ } & Thông tốt & 13 & \multicolumn{2}{|c|}{92,86} \\
\hline & Tắc mạch & $1 * *$ & \multicolumn{2}{|c|}{7,14} \\
\hline
\end{tabular}

*: Một bệnh nhân cắt cụt $1 / 3$ dưới cẳng chân do hoại tử ướt bàn chân

**: Tắc cầu đùi - khoeo sau môt lấy huyết khối 1 tuần, stent trên thông tốt

\section{BÀN LUẬN}

\subsection{Lịch sử phương pháp điều trị Hybrid}

Năm 1973, Porter JM báo cáo trường hợp lâm sàng đầu tiên phối hợp giữa phẫu thuật (bắc cầu đùi khoeo) và can thiệp (nong ĐM đùi nông bằng bóng) với kết quả lâm sàng rất tốt [0]. Đây là ca Hybrid đầu tiên được báo cáo trên thế giới. Từ đó tới nay, phối hợp giữa phẫu thuật và can thiệp mạch máu tại phòng mổ Hybrid trở thành xu hướng chung tại các nước phát triển với vai trò quan trọng của phẫu thuật viên[0].

Tại Việt Nam, ca Hybrid đầu tiên được tiến hành ngày 11/10/2011 tại Bệnh viện Hữu nghị Việt Đức trên một BN nam 69 tuổi có hẹp hai miệng nối của cầu nối đùi khoeo trái cũ, chân thiếu máu g/đ III. Phương pháp điều trị là Hybrid làm lại miệng nối đùi, nong và đặt stent cho miệng nối khoeo với stent số 7 . BN hết đau và ra viện sau điều trị 4 ngày. Kết quả của $B N$ là khích lệ lớn cho chúng tôi. Giai đoạn 2011 đến 2013 chúng tôi đã tiến hành can thiệp cho $8 \mathrm{BN}$ với kết quả điều trị tốt[0].

\subsection{Về đặc điểm dịch tễ}

Đa phần $\mathrm{BN}$ đều là nam giới và có hút thuốc lá. Rõ ràng hút thuốc là một yếu tố nguy cơ cao trong bệnh lý mạch máu nói chung và gắn liền với giới nam. Tuổi trung bình của $\mathrm{BN}$ là 72,7 tương ứng với tuổi mắc bệnh mạch máu tại châu Âu (62-73 tuổi) [0]. Con số này cao hơn kết quả nghiên cứu trước của chúng tôi là 70,6[0] có lẽ do chất lượng cuộc sống, tuổi thọ trung bình của $\mathrm{BN}$ tại Việt Nam được cải thiện và $\mathrm{BN}$ có điều kiện hơn để tiến hành phẫu thuật - can thiệp so với giai đoạn trước đây.

Bệnh ĐM chi dưới nằm trong bệnh lý xơ vữa mạch máu toàn thân nên số $\mathrm{BN}$ của chúng tôi có tổn thương các mạch máu khác tương đối cao. Kết quả này cũng tương ứng theo các nghiên cứu tại châu Âu[0]. Tỷ lệ BN có tai biến mạch não cũ, tổn thương mạch cảnh trên siêu âm và tổn thương mạch vành trên chụp mạch chiếm tỷ lệ cao trên $20 \%$ (Bảng 1). Tổn thương mạch máu nhiều tầng cũng là một bằng chứng cho thấy bệnh lý này ảnh 
hưởng đến mạch máu tại nhiều vị trí. Dưới đây là phải can thiệp và tổn thương cả ba tầng mạch một $\mathrm{BN}$ có có thiếu máu chi giai đoạn IV cần máu (Ảnh 1).
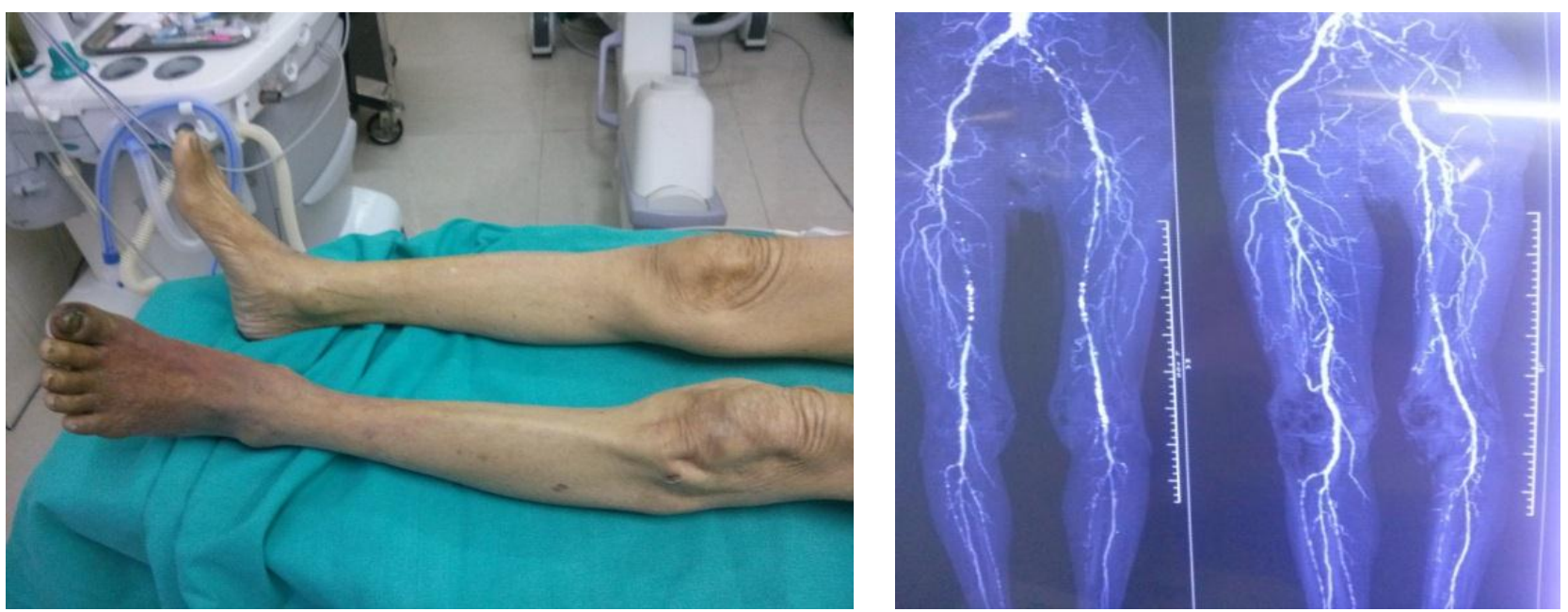

Hình 1. Lâm sàng và phim MSCT của bệnh nhân thiếu máu chân trái g/ă IV

\subsection{Về chỉ định điều trị}

Có thể chỉ định hybrid cho nhiều loại tổn thương mạch máu khác nhau, áp dụng linh hoạt cho $\mathrm{BN}$ cấp cứu hoặc có kế hoạch (3 $\mathrm{BN}$ của chúng tôi được chỉ định mổ cấp cứu có trì hoãn). Tổn thương mạch có thể là thương tổn hẹp, tắc hoàn toàn, huyết khối mới gây tắc cầu nối cũ. Áp dụng Hybrid không chỉ giúp chúng tôi tiết kiệm

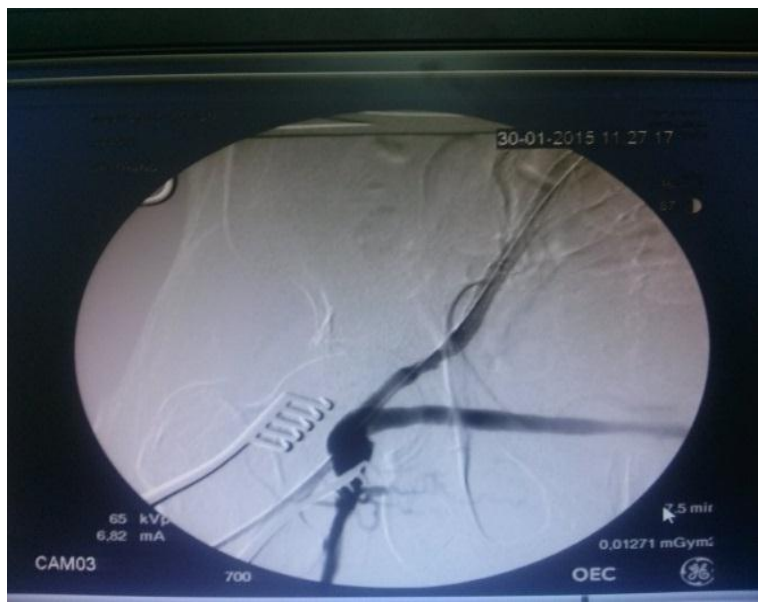

thời gian chẩn đoán (đánh giá tổn thương bằng chụp mạch trong khi phẫu thuật) mà còn giúp đánh giá kết quả điều trị ngay sau đó (Ảnh 2).

Với BN có mổ cũ, áp dụng Hybrid sẽ giúp chúng tôi tránh phải mổ lại trên cả hai vị trí của cầu nối cũ, tránh được các tổn thương viêm dính cũ rất khó xử lý (3 $\mathrm{BN}$ - bảng 1$)$.

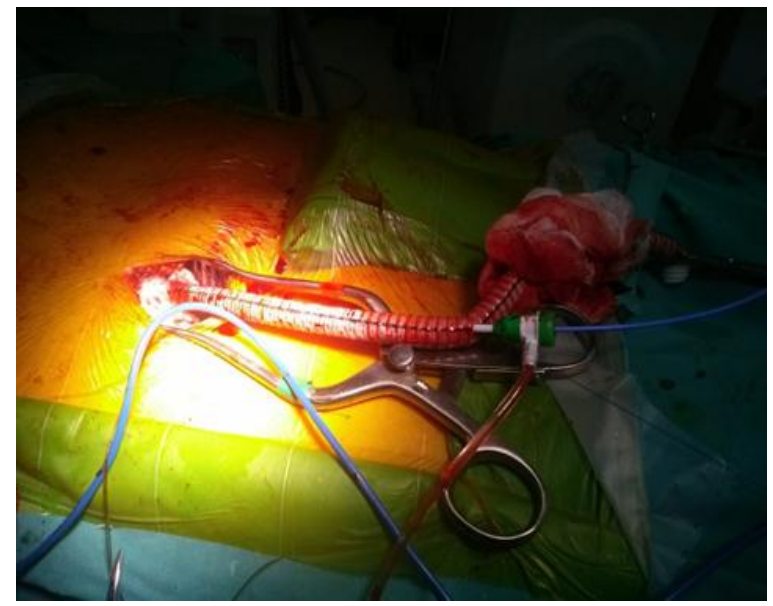

Hình 2. Chụp kiểm tra sau Hybrid (ảnh trái) và đưòng vào qua mạch nhân tạo (phải) 


\subsection{Về kết quả điều trị}

Cùng với các ưu điểm đã được khẳng định tại các nghiên cứu trước như giảm thời gian điều trị, giảm thời gian nằm viện, Hybrid vẫn còn những hạn chế nhất định như chi phí điều trị còn cao, việc tiếp xúc với phóng xạ của cả $B N$ và nhân viên y tế, các nguy cơ của bệnh và việc sử dụng thuốc cản quang [2],[0]. Can thiệp mạch máu trên nền mạch bệnh lý cùng với việc sử dụng thuốc chống đông dẫn tới rất nhiều biến chứng bao gồm chảy máu, giả phồng, lóc tách mạch máu [0]. Khi phối hợp phẫu thuật và can thiệp, chúng tôi có thể kiểm soát chảy máu tốt hơn so với chỉ can thiệp đơn thuần. Một trong những cải tiến của chúng tôi trong giai đoạn này là tạo thêm các đường vào cho can thiệp nội mạch để tránh các biến chứng liên quan đến vị trí chọc mạch can thiệp (Can thiệp qua đường vào mạch nhân tạo ở ảnh 2). Chính vì vậy tất cả các $\mathrm{BN}$ của chúng tôi đều không gặp một biến chứng nào liên quan đến chảy máu và lóc tách thành mạch. Ở các $\mathrm{BN}$ cao tuổi, việc hạn chế các biến chứng này mang tính chất sống còn. Thành công về mặt kỹ thuật của chúng tôi là $100 \%$ (bảng 3). Mặc dù kinh nghiệm của chúng tôi là chưa nhiều tuy nhiên nếu lựa chọn bệnh nhân tốt, đúng chỉ định và tiến hành kỹ thuật một cách cẩn thận, bài bản sẽ đem lại hiệu quả cho tất cả bệnh nhân.

Chỉ định cắt cụt ở các $\mathrm{BN}$ có thiếu máu giai đoạn IV là cần thiết trong trường hợp vùng hoại tử rộng, có hoại tử ướt. Trong $6 \mathrm{BN}$ của chúng tôi chỉ có 4 trường hợp phải cắt cụt (bảng 3 ) do $2 \mathrm{BN}$ còn lại có loét hồi phục hoặc vùng hoại tử có thể tích nhỏ. Việc không phải cắt cụt của $2 \mathrm{BN}$ này cho thấy tác dụng của điều trị làm ngừng tiến triển của hoại tử chi. $\mathrm{BN}$ phải cắt cụt $1 / 3$ dưới cẳng chân là $\mathrm{BN}$ có hoại tử ướt bàn chân. Nếu không phục hồi lưu thông mạch $\mathrm{BN}$ sẽ phải cắt cụt chi đến đùi. Như vậy hybrid ngoài tác dụng giảm đau ở tất cả các bệnh nhân (bảng 3) còn có tác dụng bảo tồn chi hiệu quả.

Hybrid mang lại hiệu quả rõ rệt về tưới máu. Chỉ số huyết áp mắt cá chân-cánh tay $\mathrm{ABI}$ là minh họa rõ nhất cho kết quả điều trị. Các $\mathrm{BN}$ của chúng tôi trước điều trị có chỉ số này trung bình là 0,23 (bệnh ĐM chi dưới mức độ nặng) tăng lên rõ rệt thành 0,73 (bệnh ĐM chi dưới mức độ vừa) sau điều trị [10]. Chỉ số này không chỉ nói lên kết quả cải thiện dòng máu sau phục hồi lưu thông mạch mà còn khẳng định kết quả giảm đau của điều trị. Một thành công nữa của Hybrid được thể hiện qua sự hồi phục về mặt giải phẫu qua chụp kiểm tra và siêu âm sau mổ. Tỷ lệ mạch thông khi ra viện lên đến 92,86\% (bảng 3).

\subsection{Những khó khăn hiện tại}

Bên cạnh những kết quả lạc quan, chúng tôi còn gặp những thách thức không nhỏ trong quá trình nghiên cứu. Đó là việc thiếu trang thiết bị, dụng cụ cho phẫu thuật và can thiệp, Hệ thống máy $\mathrm{C}$-arm cỡ nhỏ, phát nhiều tia phóng xạ, chi phí vật tư cao, chưa được thanh toán bảo hiểm. Đa phần các $\mathrm{BN}$ đến muộn, tổn thương lan tỏa và khó áp dụng điều trị triệt để các tổn thương. Không chỉ là khó khăn về $\mathrm{BN}$, chúng tôi còn gặp nhiều khó khăn trong sự đồng thuận của gia đình người bệnh, một phần là do chi phí, một phần là do bệnh tái đi tái lại, việc chăm sóc cho $\mathrm{BN}$ ở các tuyến cơ sở còn khó khăn, tâm lý ngại điều trị cho $\mathrm{BN}$ cao tuổi. Mặt khác kinh nghiệm điều trị của chúng tôi còn chưa nhiều và thời gian được đào tạo cần lâu dài hơn, tại các cơ sở có nhiều kinh nghiệm.

\section{KẾT LUẬN}

Với kết quả sớm tốt, phối hợp phẫu thuật và can thiệp nội mạch (Hybrid) là một hướng đi đúng đắn cần được tiếp tục nghiên cứu mở rộng cho các $\mathrm{BN}$ có tổn thương nhiều tầng của bệnh ĐM chi dưới. Vấn đề theo dõi lâu dài cần được 
nghiên cứu thêm cho các $\mathrm{BN}$ này do tổn thương tại nhiều mạch máu trên cùng một $\mathrm{BN}$. Tuy còn nhiều khó khăn như thiếu trang thiết bị, chi phí y tế còn cao, năng lực con người còn hạn chế, tâm lý BN tuổi cao, ngại đi khám lại. Việc lựa chọn và giải thích bệnh nhân hợp lý, tăng cường đào tạo nhân lực chuyên sâu, thực hành thường xuyên, trang bị đầy đủ, cải thiện chế độ bảo hiểm xã hội sẽ giúp phương pháp điều trị này có kết quả ngày một tốt hơn.

\section{TÀI LIỆU THAM KHẢO}

1.Đoàn Quốc Hưng. (2011) "Can thiệp nội mạch và phối hợp phẫu thuật mổ mở-can thiệp nội mạch: xu hướng mới trong điều trị bệnh mạch máu”. Tạp chí nghiên cứu y học: 80;354: 64-60.

2.Nguyễn Duy Thắng, Đoàn Quốc Hưng, Nguyễn Hữu Ước, Phạm Quốc Đạt (2013) “Kết quả phối hợp phẫu thuật và can thiệp nội mạch một thì (Hybrid) trong điều trị bệnh lý mạch máu tại bệnh viện hữu nghị Việt Đức". Tạp chí y học thực hành số 7(876): 43-46

3.Đoàn Quốc Hưng, Nguyễn Duy Thắng, Nguyễn Hữu Ước, Lê Thanh Dũng, Nguyễn Lân Hiếu (2014) "Điều trị bệnh mạch máu phức tạp bằng can thiệp nội mạch phối hợp phẫu thuật (Hybrid)" Tạp chí tim mạch học Việt Nam số 65: 34-41.

4.Alan T. Hirsch et al. (2006) "ACC/AHA 2005 Practice Guidelines for the Management of
Patients With Peripheral Arterial Disease (Lower Extremity, Renal, Mesenteric, and Abdominal Aortic)". Circulation.113:e463-e654

5.Michal Tendera et al (The Task Force on the Diagnosis and Treatment of Peripheral Artery Diseases of the European Society of Cardiology (ESC)) (2011) "ESC Guidelines on the diagnosis and treatment of peripheral artery diseases" European Heart Journal 32, 2851-2906.

6.Rooke Twet al. (2011) "ACCF/AHA focused update of the guideline for the management of patients with peripheral artery disease (updating the 2005 guideline)". Catheter Cardiovasc Interv. 2012 Mar 1;79(4):501-31.

7.Porter JM, Eidemiller LR, Dotter CT, Rösch J, Vetto RM: (1973) "Combined arterial dilatation and femorofemoral bypass for limb salvage”. Surg Gynecol Obstet 137:409-412.

8.Goodney P.Philip, R. M. Zwolak. (2009) National trends in lower extremity bypass surgery, endovascular intervention, and major amputations. J Vasc Surg 50:54-60

9.Ortiz D1, Jahangir A1, Singh M1, Allaqaband S1, Bajwa TK1, Mewissen MW2 2014 "Access site complications after peripheral vascular interventions: incidence, predictors, and outcomes". Circ Cardiovasc Interv. Dec;7(6):821-8.

10. Kenneth Ouriel (2001) "Peripheral arterial disease" Lancet; 358: 1257-64. 